\title{
Patologias inflamatórias sistêmicas do pé Visão do reumatologista
}

\author{
Débora Egri*
}

Os pés são freqüentemente acometidos pelas patologias reumatológicas, tanto quanto nos referimos às patologias de ordem inflamatória, degenerativas, infecciosas, auto-imunes e metabólicas.

É importante ressaltar, que ao depararmos com uma queixa referente a tal segmento, executemos um exame físico e uma história minuciosa, para que possamos identificar anormalidades biomecânicas congênitas, familiares ou adquiridas, assim como observamos alterações funcionais e limitações que possam nos auxiliar na compreensão dos acometimentos que estamos observando, assim como nos auxiliar na escolha do tratamento que será empregado, para que possamos corrigir alterações preexistentes e prevenir tanto o agravamento, quanto o desenvolvimento de deformidades, diminuindo a incidência de dor e de limitação funcional.

Para tanto, devemos incluir em nosso questionamento, as habilidades do paciente antes do aparecimento da patologia que o trouxe ao nosso consultório, assim como a presença de dor ou desconforto associado a de calçados e/ou terrenos.

A avaliação do paciente inclui uma avaliação articular, neurológica, vascular e tegumentária, assim como a avaliação da marcha, índice de motilidade e força muscular.

O estudo radiológico, com e sem carga, é fundamental para avaliarmos a extensão das alterações ósseas e articulares, assim como as alterações mecânicas e funcionais, para que saibamos qual será o tratamento que mais beneficiará o paciente.

Aqui selecionamos as patologias reumatológicas que mais freqüentemente trazem em sua história acometimento dos pés.

\section{Osteoartrose}

Um estudo realizado pela National Health entre 1960 e 1962, revelou que a prevalência de acometimento osteoartrótico em pés era de $20 \%$ na população entre 18 e 79 anos de idade, havendo uma maior concentração entre a quinta e a sétima década. A incidência entre os indivíduos entre 75 e 79 anos nesse mesmo estudo era de $48,6 \%$ em homens e $53,1 \%$ em mulheres, sendo, em geral, mais graves em mulheres. 
Do ponto de vista biomecânico, algumas alterações mecânicas funcionais do pé podem produzir dor e disfunção. O uso contínuo ou excessivo de um pé biomecanicamente deficiente, associado ao trauma, é, provavelmente, o fator precipitante mais comum de doenças degenerativas dos pés.

O acometimento osteoartrótico dos pés afeta, tipicamente, a primeira articulação metatarsofalangeana, ocorrendo sobretudo no sexo feminino e guardando uma incidência familiar aumentada.

Os pacientes com tal acometimento usualmente apresentam diminuição da tolerância para calçados, especialmente aqueles que são justos ou possuem a ponta fina.

Existem padrões de osteoartrose que são típicos dos pés, destacando-se:

- Halux rigidus: A perda progressiva da mobilidade da primeira MTF pode surgir após traumatismo ou hálux valgo, assim como estar associada a pé plano, pé pronado ou primeiro metatarso varo. Tal quadro é observado sobretudo em adolescentes e adultos jovens que se caracteriza pela restrição dolorosa da dorsiflexão da primeira metatarsofalangeana. O hálux rigidus, muitas vezes, é mais incapacitante que o hálux valgo.

- Halux valgus: trata-se também de um padrão comum de OA de primeira MTF, que se caracteriza pela angulação lateral, ou seja, fibular, do primeiro dedo, podendo observar-se ao $\mathrm{RX}$ esclerose proeminente, formação de cistos $\mathrm{e}$ osteofitose na borda medial de tal articulação. Freqüentemente, tal deformidade é acompanhada de bursa adventícia dolorosa e mole, que uma vez inflamada causa dor. Na ausência de patologia inflamatória ou doença do tecido conectivo, esta deformidade está correlacionada com fatores estruturais. Em geral acomete pessoas, particularmente entre 30 e 50 anos, que possuem fatores predisponentes para o desenvolvimento destas deformidades, tais como obesidade, calçados inapropriados e períodos prolongados de uso excessivo dos pés.

- Dedos em martelo: Trata-se da deformidade mais comum dos demais pododáctilos, podendo ser única ou múltipla. Caracteriza-se pela hiperextensão da articulação MTF associada a flexão da IFP, de tal sorte que o dedo fica com a ponta voltada para baixo. Em geral, trata-se de um distúrbio adquirido e resulta da compressão por hálux valgo e sapatos apertados, podendo ainda ser congênito. Com freqüiência, uma bursa dolorosa e calosidade se formam na face dorsal das articulações IFP fletidas. A ponta do dedo se alarga e se espessa.
O padrão radiológico observado na OA é a diminuição do espaço articular, esclerose óssea, formação de osteofitos e presença de cistos subcondrais.

\section{Artrite reumatóide}

O acometimento dos pés como sintomas inicial de A.R. é observado em 17 a 20\% dos pacientes, sendo que, com o progredir da doença, tal índice atinge cerca de $90 \%$ dos pacientes, dos quais mais de $1 / 3$ terão acometimento significativo, sempre lembrando que raramente há acometimento de I.F.D. em A.R.

As queixas dos pacientes referem-se a dor, edema, rigidez matinal e alteração da marcha. Graças a natureza difusa da dor, usualmente o paciente encontra dificuldades em localizar exatamente o ponto álgico. Ao exame físico, temos que a compressão látero-lateral das cabeças dos metatarsos aumentam a dor. Sensibilidade aumentada entre as cabeças dos metatarsos indicam envolvimento de estruturas periarticulares, sendo que, diante de tal achado, devemos atentar para a possibilidade de estarmos diante de um neuroma plantar.

Evidências clínicas de envolvimento de tornozelos é a presença de edema cístico anterior e posteriormente ao maléolo. A maior parte da estabilidade do tornozelo depende da integridade dos ligamentos entre a fibula e a tíbia e destes com os dois ossos dos talos. na A.R., os fenômenos inflamatórios e proliferativos podem fazer com que haja perda de tais conexões, por erosão e estiramento dos ligamentos. Tais fenômenos resultam em incongruência articular, que uma vez estabelecida, progride para deformidade em pronação e eversão dos pés.

O tendão de Aquiles é muito importante na estrutura e na cinética do pé e do tornozelo. Pode ser acometido por nódulos reumatóides e sua ruptura espontânea é relatada quando temos inflamação granulomatosa difusa.

A articulação subtalar controla a eversão e a inversão do pé e está freqüentemente envolvida na A.R., ocasionando aumento da dor e deambulação em terrenos acidentados.

O pé aumenta à medida que aumenta o ângulo entre os metacarpos. As articulações MTF são freqüentemente envolvidas e a marcha é alterada havendo dor no início do passo. A subluxação para baixo das cabeças dos metatarsos ocorrem depois que as articulações MTF estão envolvidas, produzindo a 
deformidade em cock-up. Hálux valgo e calosidades também são observados.

Coleções císticas em bainhas de tendões de flexores também são observados e freqüentemente se desenvolvem embaixo das MTF.

Pacientes com subluxação das cabeças dos metatarsos para a área subcutânea podem desenvolver necrose por pressão. Alternativamente, pacientes que possuem subluxação de articulares MTF podem desenvolver necrose por pressão acima das IFP, que estão protusas dorsalmente (dedos m martelo) e estão sujeitas ao atrito com o sapato.

A seqüência de alterações progressivas em pés são as seguintes:

1. estiramento dos ligamentos da articulação intrametatarsal;

2. alargamento do ante-pé;

3. o coxim fibrogorduroso da superfície plantar migra anteriormente;

4. subluxação dorsal dos dedos, com encurtamento dos tendões extensores;

5. subluxação das cabeças dos metatarsos para a área subcutânea da superfície plantar; e

6. desenvolvimento de hálux valgo, freqüentemente resultando em encavalamento dos segundo e terceiro dedos sobre o primeiro dedo.

Uma outra causa de dor no pé reumatóide é a síndrome do túnel do tarso. Tal quadro consiste de uma neuropatia de encarceramento do nervo tibial posterior quando este passa pelo retináculo flexor, na face medial do tornozelo. Clinicamente estes pacientes queixam-se de dolorimento, queimação, parestesia e formigamento na superfície plantar do pé, na porção distal do mesmo, nos pododáctilos e, ocasionalmente, no calcanhar. A dor também pode ser irradiada para panturrilha. O desconforto costuma ser noturno, piorando quando o paciente se levanta, muitas vezes sendo difícil distinguir as queixas apresentadas na presença deste acometimento com aquela observada nos pacientes com AR sem compressão.

A avaliação radiológica do pé reumatóide esbarra muitas vezes nas dificuldades de distinguirmos claramente o que é uma alteração inflamatória primária, das complicações osteoartríticas secundárias, sobretudo em estadios avançados da doença. Os achados radiológicos mais freqüentes são:

1. edema de partes moles

2. osteopenia justarticular

3. diminuição de espaço articular

4. cistos, erosões ósseas

5. desalinhamento

\section{Síndrome de Reiter}

A SR acomete preferencialmente tendão de Aquiles, fáscia plantar, tornozelos e articulação subtalar.

Os dedos em salsicha (dactilite), que decorrem da presença de edema extrasinovial, são característicos dos processos entesopáticos e representam uma lesão típica da S.R.

$\mathrm{O}$ acometimento ungueal pode ser observado tanto como manifestação isolada como em associação com o queratoderma. Nos estágios iniciais temos hiperemia periungueal, assim como amolecimento da lâmina ungueal, sendo que com o progredir da lesão temos acúmulo material córgeo amarelado no leito subungueal e a presença de uma lâmina fina é destruída.

Ao exame radiológico dos pés, nada é observado nas fases iniciais, sendo que com a progressão da doença podemos observar osteopenia junta-articular, diminuição de espaço, assim como erosões. Periostite em metatarsos, tarsos e falanges também são descritos. Neo-formação óssea é encontrada na inserção da fáscia plantar.

\section{Artrite psoriática}

Trata-se de uma doença incomum na população e provavelmente ocorre em 5\% dos indivíduos com psoríase.

O padrão de acometimento articular é bastante variável, sendo que uma de suas maiores características é o envolvimento predominante das articulações I.F.D..

Na forma oligoarticular assimétrica, que representa cerca de $50 \%$ dos pacientes, temos nos pés envolvimento de IFP, I.F.D. e MTF, assim como podemos encontrar dactilite.

Os pés também são acometidos na forma com envolvimento predominante de I.F.D., onde encontramos a chamada unha psoriática e representa de 5 a $10 \%$ dos pacientes.

Cerca de $5 \%$ dos pacientes desenvolvem a chamada artrite mutilante, onde observamos osteólise de falange distal, ocasionando deformidades severas, descritas como "telescopagem" e "opera glass".

Nos casos de poliartrite simétrica, que representa cerca de $25 \%$ dos casos, podemos ter acometimento semelhante com o observado na A.R.

\section{L.E.S.}

Tenossinovite, com inflamação de ligamentos, tendões e/ou cápsula articular é observado em 
$10,13 \%$ dos pacientes, sendo que a nível de pés, pode promover faceíte plantar, assim como tendinite de Aquiles e de tendinite tibial posterior. A ruptura de T. de Aquiles é rara, ocorrendo sobretudo em homens.

\section{Arterite gotosa aguda}

Cerca de 19\% dos indivíduos portadores de gota apresentam pelo menos 1 episódio de podagra, ou seja, crise de artrite em primeira articulação MTF. Tal quadro ocorre como manifestação inicial de artrite gotosa em aproximadamente $50 \%$ dos pacientes, sendo que o acometimento bilateral na primeira crise ocorre em $5 \%$ desses indivíduos.

Nos pés dos portadores de gota, também podemos observar a presença de tofos, inclusive em topografia de tendão de Aquiles. Os tofos apresentam progressão insidiosa, e, eventualmente, podemos observar destruição articular e desenvolvimento de deformidades grotescas, principalmente em mãos e em pés, sendo a anquilose óssea rara.

Ao Rx pode-se observar a formação de erosões ósseas marginais a nível de articulações I.F., com bordas escleróticas, assim como podemos também detectar a presença de cistos ósseos.

\section{Artrite de Jaccoud}

Classicamente descrita para a Febre Reumática, quadros que lembram tal manifestação também podem ser observados na presença de L.E.S., DMTC, SS e, mais raramente em outras patologias inflamatórias sistêmicas. Trata-se de um quadro de artrite crônica, descrito classicamente para mãos, sendo que em 1984, Joseph e cols. (J. Joint Surg). descreveram o caso de um paciente que, após um quadro de cardite por F.R., desenvolveu desvio medial de primeira metatarso, de forma bilateral, sem que se pudesse observar a presença de erosão óssea ao $R x$, sendo que foi evidenciada a presença de fibrose periarticular no ato operatório.

\section{Osteoartropatia hipertrófica}

O.H. pode ser definida como uma síndrome caracterizada por:

1. periostite proliferativa de ossos longos;

2. baqueteamento digital;

3. oligo e/ou polisinovite.

$\mathrm{O}$ baqueteamento digital foi descrito inicialmente por Hipócrates, mas sua associação com artrite e doença cardíaca pulmonar crônica foi elaborada em 1889. Subseqüentemente, a forma familiar de O.H. foi descrita em homens jovens. Mais recentemente, a tríade periostite, baqueteamento e artrite foi associada com várias doenças extratoráxicas.

\section{Artropatia de Charcot}

Trata-se de um quadro de artrite degenerativa inflamatória, cujo desenvolvimento está correlacionado apenas com a presença de neuropatia. A perda de sensibilidade dolorosa, assim como a falta de resposta proprioceptiva a nível articular e periarticular, faz com que a articulação exceda seus índices normais de mobilidade e leva ao desenvolvimento de importante instabilidade articular, culminando com o desenvolvimento de deslocamentos e deformidades. Tal quadro é observado sobretudo no DM, mas várias outras patologias que são acompanhadas de diminuição da sensibilidade levam ao desenvolvimento da artropatia de Charcot, dentre eles a sífilis terciária, a seringomielia e o alcoolismo.

Tipicamente, na apresentação inicial, o pé de Charcot é quente, edemaciado e pouco doloroso. Uma deformidade comum é o alargamento da região mediotarsal, que tem suas estruturas colapsadas e destruídas. Trata-se de um quadro tipicamente monoarticular.

Ao $\mathrm{Rx}$, inicialmente temos derrame articular, edema de partes moles e desmineralização, sendo que, quando existem osteofitos, pode ser difícil diferenciá-lo de um quadro de OA. A presença de subluxação, debris paraarticulares e fragmentação óssea, associados a história clínica do paciente, nos leva ao diagnóstico sugestivo da artropia neuropática. Com o progredir da doença a presença de reabsorção do osso subcondral, desalinhamento articular, assim como fraturas, poderão estar presentes. 